\title{
Commentary: This case is closed
}

\author{
Carl L. Backer, MD
}

From the Division of Cardiovascular-Thoracic Surgery, Ann \& Robert H. Lurie Children's Hospital of Chicago, Northwestern University Feinberg School of Medicine, Chicago, Ill.

Disclosure: Dr Backer is a consultant for W.L. Gore \& Associates.

Received for publication Sept 4, 2019; accepted for publication Sept 5, 2019; available ahead of print Oct 17, 2019.

Address for reprints: Carl L. Backer, MD, Division of Cardiovascular-Thoracic Surgery, Ann \& Robert H. Lurie Children's Hospital of Chicago, 225 E. Chicago Ave, mc 22, Chicago, IL 60611 (E-mail: cbacker@ luriechildrens.org).

J Thorac Cardiovasc Surg 2020;159:1028

0022-5223/\$36.00

Copyright $(2019$ by The American Association for Thoracic Surgery

https://doi.org/10.1016/j.jtcvs.2019.09.026

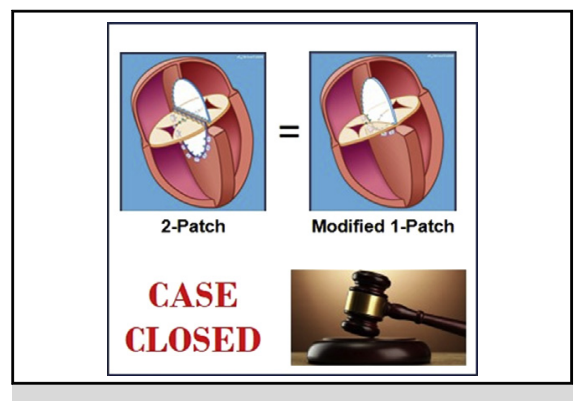

2-patch $=$ modified 1 -patch technique.

Central Message

In a review of more than 800 patients undergoing surgical repair of complete atrioventricular septal defect, there was no difference in outcomes comparing modified single-patch with the double-patch technique.

See Article page 1014. valve reintervention, incidence of left ventricular outflow tract obstruction, or need for pacemaker placement. For the past 20 years this topic has been the subject of countless debates at our national meetings. In fact, 8 of the references for this manuscript are formal comparisons of the 2 techniques. I believe that the very comprehensive and thorough propensity matching of this analysis has finally settled the debate.

Surgeons and centers experienced in doing either 1 of these 2 operations for CAVSD actually have very similar excellent results. It should be noted, however, that there are other factors that contribute to these results. One is the timing of the surgery, with a median age of 3 months and weight of $4.5 \mathrm{~kg}$. Surgical repair of CAVSD at this age helps avoid the postoperative complication of pulmonary hypertension, and the atrioventricular (AV) valve insufficiency associated with progressive dilatation of the AV annuli over time. A second factor is that in Australia there appears to be regionalization of care, with 4 large centers accounting for these 800 cases.

Another interesting observation is that the Australians seem to have abandoned the classic single-patch technique. In my opinion, this technique has been associated with the greatest incidence of reoperation for left AV valve insufficiency, and it appears that it is slowly being abandoned. One point that the authors did not emphasize but they continue to confirm is that the modified single-patch technique is associated with shorter cardiopulmonary bypass and aortic crossclamp times. The other factor that I have found useful regarding the modified single-patch technique is that it is a much easier technique to teach to congenital cardiac surgical fellows in training.

One final problem remaining with both techniques is residual left AV valve regurgitation. This was the most

common indication for reoperation in both groups, and nearly $10 \%$ of both cohorts required left AV valve reintervention. This underscores the importance of a great deal of attention being paid to the left AV valve at the time of the initial operation. Interestingly, the authors note only 2 patients having reoperation for left AV valve stenosis. It may be an important finding from this manuscript that when repairing the left AV valve, we should err toward the side of residual left $\mathrm{AV}$ valve stenosis rather than leaving left $\mathrm{AV}$ valve regurgitation. Curiously, the zone of apposition was closed in almost all patients who had a modified singlepatch technique but only $50 \%$ of the patients who had the double-patch technique. That being said, there was still no difference in reoperation rates for left $\mathrm{AV}$ valve insufficiency. This is a curiosity that I find difficult to explain.

Congratulations to the Australian centers. Their regionalization of care and early operation for CAVSD has led to excellent outcomes with both the modified single-patch technique and the double-patch operation. The authors have truly settled the ongoing debate over which technique is "better." One unfortunate consequence is that we will no longer be able to use this topic for lively discussions regarding these patients at our meetings. The meetings will now have to focus on improving the results of left AV valve repair. This case is now closed.

\section{Reference}

1. Fong LS, Betts K, Bell D, Konstantinov IE, Nicholson IA, Winlaw DS, et al; the Australian CAVSD study group. Results of complete atrioventricular septal defect repair over 25 years in Australia. J Thorac Cardiovasc Surg. 2020;159:1014-25.e8. 